\title{
CRESCIMENTO DE MILHETO E GUANDU, DESEMPENHO DE PLANTAS CÍTRICAS E PROPRIEDADES FÍSICAS DO SOLO ESCARIFICADO EM UM POMAR ${ }^{(1)}$
}

\author{
Ivan Bordin ${ }^{(2)}$, Carmen Silvia Vieira Janeiro Neves ${ }^{(3)}$, Pedro Francio Filho ${ }^{(4)}$, \\ Edilene Aparecida Preti ${ }^{(4)} \&$ Carina Cardoso ${ }^{(4)}$
}

\begin{abstract}
RESUMO
Escarificação do solo e plantas de cobertura em pomares podem ser utilizados para melhorar as condições físicas do solo. Este trabalho teve como objetivo avaliar a influência da escarificação no crescimento de adubos verdes, no desempenho das árvores e em propriedades físicas de um Latossolo Vermelho distroférrico, num pomar cítrico com histórico de compactação. Foi realizada uma escarificação à profundidade de $0,30 \mathrm{~m}$, seguida por três tipos de plantas de cobertura: vegetação espontânea, guandu (Cajanus cajan) e milheto (Pennisetum americanum). O delineamento experimental utilizado foi o inteiramente aleatorizado, num fatorial 2 x 3 (escarificado e não-escarificado e três plantas de cobertura do solo). Para as coberturas do solo, foi avaliada a fitomassa da parte aérea e abertas trincheiras para avaliação do crescimento das raízes. As plantas cítricas foram avaliadas com relação a seu crescimento e produção. Os atributos físicos do solo foram determinados em três locais (copa, rodado e entrelinha) e quatro profundidades $(0-0,1 ; 0,1-0,2 ; 0,2-0,3 ;$ e $0,3-0,4 \mathrm{~m})$. A fitomassa da parte aérea do guandu e a do milheto aumentaram com a escarificação do solo. O crescimento do sistema radicular do milheto foi maior do que o do guandu no manejo escarificado e igual ao deste no manejo não-escarificado. $O$ crescimento e a produção das plantas cítricas não foram influenciados pelos tratamentos. Houve aumento da macroporosidade do solo e redução da densidade e da resistência do solo à penetração com a escarificação do solo.
\end{abstract}

Termos de indexação: raiz, plantas de cobertura, porosidade, densidade do solo, resistência do solo à penetração.

\footnotetext{
(1) Trabalho de Tese de Doutorado do primeiro autor apresentado ao Programa de Pós-graduação em Agronomia, Universidade Estadual de Londrina - UEL. Trabalho financiado pelo CNPq. Recebido para publicação em agosto de 2007 e aprovado em junho de 2008.

(2) Engenheiro-Agrônomo, Doutorando em Agronomia, Universidade Estadual de Londrina - UEL. Caixa Postal 6001, CEP 86051990 Londrina (PR). E-mail: ivanbordin@uel.br

(3) Professora Associada, Departamento de Agronomia, UEL. Bolsista produtividade CNPq. E-mail: csvjneve@uel.br

(4) Acadêmico de Agronomia, UEL. E-mails: francio_pf@hotmail.com; edipretti2006@yahoo.com.br
} 


\title{
SUMMARY: GROWTH OF MILLET AND PIGEON PEA, PERFORMANCE OF CITRUS TREES, AND SOIL PHYSICAL PROPERTIES IN A CHISELLED ORCHARD
}

\begin{abstract}
Chiseling and cover crops can be used in the management of orchards with the purpose of improving soil physical conditions and reducing soil compaction. This study had the objective of evaluating the influence of chiseling on the development of cover crops and citrus trees and on soil physical properties in an orchard with a compaction history in a clayey Typic Haplorthox. The soil was chiseled at $0.30 \mathrm{~m}$, followed by three soil cover crops: spontaneous vegetation, pigeon pea (Cajanus cajan), and millet (Pennisetum americanum). The statistical design was completely randomized in a factorial $2 \times 3$ (chiseling and nonchiseling and three soil covers). After 110 days the aboveground phytomass of cover crops was collected and trenches were dug for root evaluation. The soil physical properties were determined at three points (under canopy, wheel track and inter-row) and four depths ( 0 $0.1 ; 0.1-0.2 ; 0.2-0.3$ and $0.3-0.4 \mathrm{~m})$. The phytomass of the aboveground part and root system of the cover crops was greater in the chiseling treatment. In the chiseling management the root growth of pearl millet was greater than of pigeon pea and equal in the unchiseled treatment. Development and yield of citrus trees were not affected by treatments. Soil chiseling resulted in a higher soil macro porosity and lower soil bulk density and soil penetration resistance.
\end{abstract}

Index terms: roots, cover crops, soil porosity, soil bulk density, soil penetration resistance.

\section{INTRODUÇÃO}

Na região norte do Paraná, a citricultura começou a ser implantada na década de 1990. Desde então, a atividade tem alcançado resultados expressivos. Atualmente a área de citros no Paraná é de 26.490 ha, com produção de 574.257,67 t de frutos no ano de 2005 e valor de $\mathrm{R} \$ 146.814 .138,40$, o que significa $25,5 \%$ do valor bruto total das frutas produzidas no Estado (Andretta, 2007).

Os pomares cítricos podem apresentar compactação do solo, proveniente do tráfego excessivo causado pelo elevado número de operações, como adubações, pulverizações e controle de plantas daninhas. $\mathrm{O}$ problema tende a se agravar na colheita das variedades tardias, que coincide com o período chuvoso, aumentando a compactação devido à passagem de carretas e caminhões (Tersi \& Rosa, 1995). A compactação ocorre principalmente em locais determinados nas entrelinhas de plantio, em razão da distribuição do peso dos implementos pelos rodados (Minatel et al., 2006).

Para reduzir a compactação do solo, pode-se fazer a escarificação, que é a operação de rompimento da camada arável (de 0,15 a 0,30 m de profundidade), ou a subsolagem, que visa romper camadas de solo abaixo da camada arável (profundidades além de 0,30-0,35 m) (Silveira, 1988). Essas operações modificam a estrutura do solo, reduzem a resistência à penetração radicular, contribuem na melhoria da circulação de ar, água e nutrientes e aumentam o volume de solo a ser explorado pelas raízes, como observado nos solos coesos dos Tabuleiros Costeiros da Bahia (Rezende et al., 2002). Entretanto, deve-se tomar cuidado com os ferimentos que os implementos podem ocasionar às raízes, por favorecerem a penetração de patógenos (Feichtenberger et al., 1994).

A associação da prática da escarificação com o cultivo de plantas de cobertura do solo que possuam sistemas radiculares profundos e agressivos, capazes de penetrar nas camadas compactadas, é recomendável no manejo nas entrelinhas dos citros (Carvalho et al., 2002). Alvarenga et al. (1995) observaram diferenças entre as espécies no que diz respeito ao aprofundamento do sistema radicular no solo, com destaque para feijão-bravo-do-ceará e guandu, que chegaram a 1,6-2,0 de profundidade. Em trabalho realizado em vasos com camadas compactadas de solo, Gonçalves et al. (2006) verificaram que o milheto foi superior na produção de matéria seca da parte aérea e no aprofundamento do sistema radicular no solo, quando comparado a amaranto (Amaranthus cruentus L.), capim-pé-de-galinha gigante (Eleusine coracana) e kenaf (Hybiscus cannabinus). Silva \& Rosolem (2002) concluíram que o cultivo anterior com guandu, milheto ou aveia-preta foi mais favorável ao crescimento radicular da soja em vasos do que com mucuna-preta, soja, sorgo, tremoço azul ou pousio.

A formação de pomares no norte do Paraná, em áreas com histórico de compactação do solo, tem resultado em baixo crescimento e desenvolvimento das plantas e conseqüente redução da produtividade, necessitando da adoção de técnicas para superar esses problemas. Por ser uma atividade recente, não há resultados acerca dos efeitos de adubos verdes aliados à escarificação sobre as propriedades físicas dos solos 
argilosos da região. Nesse contexto, este trabalho teve como objetivo avaliar a influência da escarificação do solo no crescimento dos adubos verdes milheto e guandu, no desempenho das plantas cítricas e em propriedades físicas do solo de um pomar com histórico de compactação.

\section{MATERIAL E MÉTODOS}

O trabalho foi realizado num pomar comercial formado por plantas de laranja 'Folha Murcha' (Citrus sinensis (L.) Osb.) enxertadas sobre limoeiro 'Cravo' (Citrus limonia Osb.), localizado no município de Rolândia - PR, cujas coordenadas geográficas são: $23^{\circ} 27^{`} \mathrm{~S}, 51^{\circ} 47^{`} \mathrm{~W}, 600 \mathrm{~m}$ de altitude, precipitação pluvial média anual de $1.610 \mathrm{~mm}$ e temperatura média anual de $21,2^{\circ} \mathrm{C}$. O solo é classificado como Latossolo Vermelho distroférrico (Embrapa, 1999), cujas características químicas e granulométricas (Quadro 1) foram determinadas conforme IAPAR (1981) e Embrapa (1997), a partir de uma amostra composta de quatro subamostras em três locais (copa, rodado e entrelinha), em quatro profundidades ( $0-0,1$; 0,1-0,2; 0,2-0,3; e 0,3-0,4 m).

A área foi cultivada com culturas anuais desde a década de 1940, seguidas por pastagem de Brachiaria decumbens de 1982 a 1985, que foi substituída por cana-de-açúcar até a implantação do pomar cítrico em 1998. O pomar com oito anos de idade, com o espaçamento de $7 \times 3 \mathrm{~m}$, constava de plantas com altura média de 2,90 m, diâmetro da copa de 3,11 m, volume médio da copa de $15,41 \mathrm{~m}^{3}$ e produção de 122 frutos por planta, o que é considerado abaixo do esperado para a idade das plantas e a região (Stenzel et al., 2005). Vistorias realizadas no pomar indicaram que o pequeno crescimento das plantas não poderia ser atribuído a problemas fitossanitários, pois elas se encontravam em boas condições e recebiam tratamento sempre que constatada a necessidade em inspeções regulares. A adubação é realizada anualmente com 0,25 kg de adubo (formulação 5-20-20) e $4 \mathrm{~kg}$ por planta de resíduo da indústria sucroalcooleira (torta de filtro), esparramados a lanço, enquanto o controle da vegetação espontânea é feito com roçada mecânica na entrelinha e herbicida glifosato (4,8 $\mathrm{g} \mathrm{L}^{-1}$ i.a.) na linha de plantio.

Os tratamentos foram: solo escarificado e nãoescarificado, seguidos de três tipos de cobertura vegetal. A escarificação foi realiza em 20/9/2006, no solo com consistência de friável a seca. O escarificador utilizado foi do tipo montado, com sete hastes inclinadas sem asa (quatro dianteiras e três traseiras), distanciadas em $0,5 \mathrm{~m}$. A escarificação foi realizada nos dois lados da copa das plantas, a 0,30 $\mathrm{m}$ de profundidade.

As coberturas do solo foram: vegetação espontânea, com predominância de gramíneas, como braquiária (Brachiaria decumbens) e capim-pé-de-galinha (Chloris distichophylla); guandu (Cajanus cajan); e milheto (Pennisetum americanum) da variedade BN-2.

A semeadura do guandu e do milheto foi realizada manualmente, em 10/10/2006, com sulcos abertos

Quadro 1. Características químicas e granulométricas de Latossolo Vermelho distroférrico nas profundidades de $0-0,1 ; 0,1-0,2 ; 0,2-0,3 ;$ e $0,3-0,4 \mathrm{~m}$ e nos locais: copa $(C)$, rodado $(\mathrm{R})$ e entrelinha (E)

\begin{tabular}{|c|c|c|c|c|c|c|c|c|c|c|c|c|}
\hline \multirow{3}{*}{ Característica } & \multicolumn{12}{|c|}{ Profundidade (m) } \\
\hline & \multicolumn{3}{|c|}{$0-0,1$} & \multicolumn{3}{|c|}{$0,1-0,2$} & \multicolumn{3}{|c|}{$0,2-0,3$} & \multicolumn{3}{|c|}{$0,3-0,4$} \\
\hline & C & $\mathbf{R}$ & $\mathbf{E}$ & C & $\mathbf{R}$ & $\mathbf{E}$ & C & $\mathbf{R}$ & $\mathbf{E}$ & $\mathbf{C}$ & $\mathbf{R}$ & $\mathbf{E}$ \\
\hline $\mathrm{MO}\left(\mathrm{g} \mathrm{dm}^{-3}\right)$ & 34,0 & 32,0 & 20,0 & 19,0 & 14,0 & 16,0 & 15,0 & 16,0 & 11,0 & 8,0 & 11,0 & 10,0 \\
\hline $\mathrm{pH} \mathrm{CaCl} 2\left(0,01 \mathrm{~mol} \mathrm{~L}^{-1}\right)$ & 5,7 & 5,8 & 5,8 & 5,6 & 5,6 & 5,5 & 5,5 & 5,4 & 5,5 & 5,5 & 5,4 & 5,7 \\
\hline$P\left(\mathrm{mg} \mathrm{dm}^{-3}\right)$ & 25,0 & 22,7 & 11,0 & 2,5 & 1,6 & 0,6 & 1,9 & 0,9 & 0,8 & 13,8 & 3,8 & 3,6 \\
\hline $\mathrm{H}+\mathrm{Al} \quad\left(\mathrm{cmol}_{\mathrm{c}} \mathrm{dm}^{-3}\right)$ & 3,7 & 3,7 & 3,4 & 4,3 & 4,3 & 4,3 & 4,3 & 4,6 & 4,0 & 5,0 & 5,0 & 4,7 \\
\hline $\mathrm{Al}^{3+}\left(\mathrm{cmol}_{\mathrm{c}} \mathrm{dm}^{-3}\right)$ & 0,0 & 0,0 & 0,0 & 0,0 & 0,0 & 0,0 & 0,0 & 0,0 & 0,0 & 0,0 & 0,0 & 0,0 \\
\hline $\mathrm{K}^{+}\left(\mathrm{cmol}_{\mathrm{c}} \mathrm{dm}^{-3}\right)$ & 0,75 & 0,78 & 0,45 & 0,55 & 0,60 & 0,53 & 0,21 & 0,53 & 0,09 & 0,06 & 0,30 & 0,05 \\
\hline $\mathrm{Ca}^{2+}\left(\mathrm{cmol}_{\mathrm{c}} \mathrm{dm}^{-3}\right)$ & 14,0 & 15,0 & 14,1 & 12,0 & 11,7 & 12,0 & 8,3 & 9,9 & 9,0 & 6,7 & 8,9 & 8,0 \\
\hline $\mathrm{Mg}^{2+}\left(\mathrm{cmol}_{\mathrm{c}} \mathrm{dm}^{-3}\right)$ & 1,6 & 1,3 & 1,2 & 0,3 & 1,0 & 1,4 & 0,7 & 1,2 & 1,4 & 1,0 & 0,7 & 1,5 \\
\hline $\mathrm{CTC}\left(\mathrm{cmol}_{\mathrm{c}} \mathrm{dm}^{-3}\right)$ & 20,0 & 20,8 & 19,2 & 17,1 & 17,6 & 18,2 & 13,5 & 16,2 & 14,5 & 12,7 & 14,9 & 14,2 \\
\hline $\mathrm{SB}\left(\mathrm{cmol}_{\mathrm{c}} \mathrm{dm}^{-3}\right)$ & 16,3 & 17,1 & 15,7 & 12,8 & 13,3 & 13,9 & 9,2 & 11,6 & 10,5 & 7,8 & 9,9 & 9,6 \\
\hline $\mathrm{V}(\%)$ & 81,6 & 82,3 & 82,1 & 75,0 & 75,6 & 76,5 & 68,3 & 71,6 & 72,5 & 61,0 & 66,6 & 67,1 \\
\hline Argila $\left(\mathrm{g} \mathrm{kg}^{-1}\right)$ & 395 & 475 & 435 & 570 & 570 & 407 & 590 & 570 & 640 & 625 & 730 & 705 \\
\hline Silte $\left(\mathrm{g} \mathrm{kg}^{-1}\right)$ & 350 & 310 & 330 & 210 & 285 & 360 & 235 & 255 & 210 & 235 & 165 & 235 \\
\hline Areia $\left(\mathrm{g} \mathrm{kg}^{-1}\right)$ & 250 & 215 & 235 & 220 & 145 & 235 & 175 & 175 & 150 & 140 & 105 & 60 \\
\hline
\end{tabular}


com enxadas no espaçamento de $50 \mathrm{~cm}$, com $12 \mathrm{e}$ 100 sementes viáveis por metro linear, respectivamente. Na implantação do experimento, o controle de plantas daninhas foi realizado com a dessecação da área com herbicida glifosato ( $4,8 \mathrm{~g} \mathrm{~L}^{-1}$ i.a.). Depois da semeadura dos adubos verdes, a utilização de herbicida ficou restrita à linha de plantio.

A avaliação da parte aérea das plantas de cobertura do solo foi realizada 110 dias após a semeadura. Para isso, os tratamentos foram roçados manualmente com foice e foram coletadas duas amostras por parcela de fitomassa em quadros de $0,5 \times 0,5 \mathrm{~m}$, nos dois lados da copa das plantas. As variáveis obtidas foram matéria verde e matéria seca determinadas em estufa de ventilação forçada a $68^{\circ} \mathrm{C}$ por $72 \mathrm{~h}$.

$\mathrm{Na}$ avaliação do sistema radicular dos adubos verdes foi utilizado o método do perfil (Böhm, 1979), em trincheiras de 1,5 m de comprimento, sendo $1 \mathrm{~m}$ na entrelinha, contemplando duas linhas de plantio dos adubos verdes e $0,5 \mathrm{~m}$ sob a copa das árvores. As trincheiras tiveram largura de $1 \mathrm{~m}$ e profundidade de 0,6 m. As raízes foram expostas com a utilização de escarificador manual, em forma de rolo, com pregos sem cabeça. Uma moldura de madeira de 1,0 x 0,6 m, dividida por fios de náilon em quadrículas de $0,05 \times 0,05 \mathrm{~m}$, foi afixada ao perfil e foi contado o número de raízes em cada quadrícula, que foi transformado em $\sqrt{ } \mathrm{x}+0,5$. Avaliou-se a distribuição das raízes a cada $0,1 \mathrm{~m}$ de profundidade e determinouse também a profundidade efetiva, que é a profundidade até onde se concentram $80 \%$ das raízes avaliadas (Klar, 1991).

As avaliações de crescimento e produção das plantas cítricas foram realizadas em 20/12/2007. A altura e o diâmetro das copas foram medidos com régua métrica graduada, sendo o diâmetro da copa obtido em dois sentidos (paralelo e perpendicular à linha de plantio) e calculada a média. $\mathrm{O}$ perímetro do tronco foi medido a $5 \mathrm{~cm}$ acima da linha de enxertia, com fita métrica. Determinou-se ainda o volume da copa pela fórmula proposta por Mendel (1956): $\mathrm{V}=2 / 3 \pi \mathrm{R}^{2} \mathrm{H}$, em que V é o volume, $\mathrm{R}$, o raio da copa, e $\mathrm{H}$, a altura da planta.
A produção foi determinada com a contagem dos frutos, cujos dados foram transformados em $\sqrt{ } \mathrm{x}+0,5$. Foram coletados 10 frutos por planta para determinação da sua massa média e cálculo da produção por planta. Foram utilizadas duas plantas úteis por parcela.

As avaliações das propriedades físicas do solo foram realizadas 110 dias após a semeadura das plantas de cobertura do solo. A macroporosidade e a densidade do solo foram determinadas coletando-se amostras de solo em anéis volumétricos, com $0,05 \mathrm{~m}$ de diâmetro e 0,051 m de altura, seguindo o método da Embrapa (1997), nas camadas de $0-0,1 ; 0,1-0,2 ; 0,2-0,3$; e $0,3-$ $0,4 \mathrm{~m}$ de profundidade, em três locais (copa, rodado e entrelinha) dentro de cada cobertura do solo (vegetação espontânea, guandu e milheto). A resistência do solo à penetração foi determinada por penetrômetro de impacto (Stolf et al., 1983), com 12 leituras em cada local. Os dados obtidos em número de impactos por $\mathrm{dm}$ foram transformados para resistência do solo à penetração (MPa). Os resultados foram apresentados em valores médios para cada $0,10 \mathrm{~m}$ de profundidade até $0,60 \mathrm{~m}$. Para determinação da umidade do solo, foram coletadas quatro amostras deste em cada local e profundidade.

O delineamento experimental utilizado foi o inteiramente aleatorizado, com quatro plantas cítricas por parcela e quatro repetições, sendo os tratamentos arranjados em esquema fatorial $2 \times 3$ (escarificado e não-escarificado e três coberturas do solo). Os dados foram submetidos à análise de variância e ao teste de Tukey a $5 \%$.

\section{RESULTADOS E DISCUSSÃO}

Quanto ao crescimento das plantas de cobertura do solo, no manejo escarificado foi obtida maior matéria verde do que no não-escarificado, para todas as coberturas avaliadas. Dentro dos manejos de escarificação não houve diferença entre as coberturas do solo (Quadro 2).

\section{Quadro 2. Matérias verde e seca das coberturas de solo em pomar cítrico submetido a escarificação do solo}

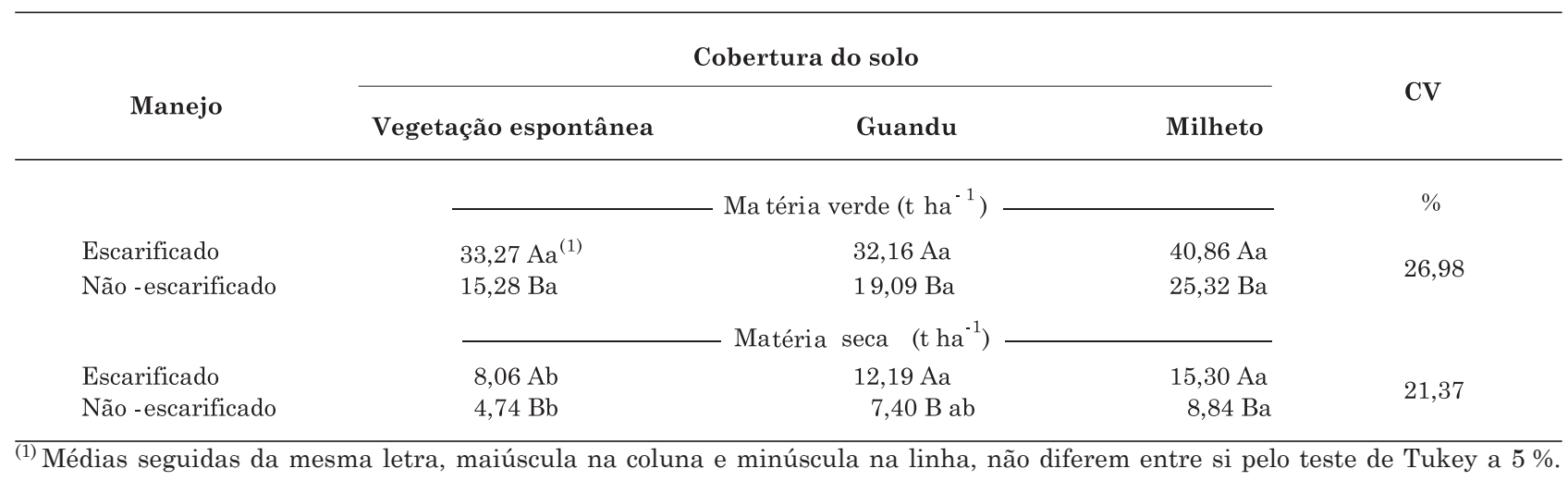


Da mesma forma, para a matéria seca, todas as coberturas do solo no manejo escarificado foram superiores às do manejo não-escarificado. Contudo, dentro do manejo escarificado, o milheto e o guandu foram superiores à vegetação espontânea, e, no manejo não-escarificado, o milheto foi superior à vegetação espontânea e igual ao guandu (Quadro 2). As diferentes respostas entre matéria verde e matéria seca também foram encontradas por outros autores, devido à variabilidade do conteúdo de água entre as espécies utilizadas (Suzuki \& Alves, 2006).

As médias de matéria seca chegaram a 12,2 $\mathrm{t} \mathrm{ha}^{-1}$ para o guandu e 15,3 t ha-1 para o milheto, no manejo escarificado, e estiveram dentro do esperado para essas culturas quando semeadas no início do verão, coincidindo com a estação das chuvas (Suzuki \& Alves, 2006). Para Alvarenga et al. (2001), a quantidade adequada de matéria seca de resíduos que proporciona elevada percentagem de cobertura do solo é de $6 \mathrm{t} \mathrm{ha}^{-1}$. No presente trabalho, apenas a vegetação espontânea no manejo não-escarificado foi inferior a esse valor, com $4,7 \mathrm{t} \mathrm{ha}^{-1}$.

No tocante ao número de raízes das plantas de cobertura no perfil do solo (profundidade de 0-0,1 m), o manejo escarificado foi superior ao não-escarificado tanto para o guandu como para o milheto, e o milheto superou o guandu nos dois manejos do solo (Quadro 3).
Ainda em relação às raízes, na profundidade de 0,1-0,2 m o manejo escarificado foi superior ao nãoescarificado somente para o milheto, enquanto o guandu não foi influenciado pela escarificação. Entre as plantas de cobertura, o milheto foi superior ao guandu apenas no manejo escarificado, mas no solo não-escarificado não houve diferença entre as coberturas. É interessante observar que nessa profundidade o guandu não apresentou diferença para a quantidade de raízes entre as condições de solo escarificado e não-escarificado. Esse fato ocorreu devido à capacidade do guandu em romper as camadas compactadas do solo, como foi observado por Silva \& Rosolem (2002).

Nas demais profundidades $(0,2-0,3 ; 0,3-0,4 ; 0,4-$ 0,5 ; e $0,5-0,6 \mathrm{~m}$ ) não foram encontradas diferenças nem para o sistema de manejo nem para as coberturas do solo. No total de raízes, o manejo escarificado foi superior ao não-escarificado para os dois adubos verdes (Quadro 3), evidenciando que o crescimento do sistema radicular das plantas no sistema não-escarificado foi influenciado pelas condições físicas do solo, apesar da boa condição química deste (Quadro 1).

Observando-se o total de raízes, o milheto superou o guandu no manejo escarificado, porém na condição não-escarificada não houve diferença entre as duas espécies (Quadro 3). O fato de não haver diferença na

Quadro 3. Número de raízes de guandu e milheto nas profundidades de $0-0,1 ; 0,1-0,2 ; 0,2-0,3 ; 0,3-0,4 ; 0,4-0,5$; e 0,5-0,6 m, número total de raízes e profundidade efetiva das raízes em pomar cítrico submetido a escarificação do solo

\begin{tabular}{|c|c|c|c|c|}
\hline \multirow{2}{*}{ Manejo } & \multicolumn{3}{|c|}{ Cobertura do solo ( ${ }^{\circ}$ de raízes) } & \multirow{2}{*}{ CV } \\
\hline & Guandu & & Milheto & \\
\hline $\begin{array}{l}\text { Escarificado } \\
\text { Não - escarificado }\end{array}$ & \multicolumn{2}{|l|}{$\begin{array}{l}323,00 \mathrm{Ab}^{(1)} \\
182,00 \mathrm{Bb}\end{array}$} & $\begin{array}{l}468,50 \mathrm{Aa} \\
252,25 \mathrm{Ba}\end{array}$ & $\begin{array}{l}\% \\
7,77\end{array}$ \\
\hline $\begin{array}{l}\text { Escarificado } \\
\text { Não - escarificado }\end{array}$ & $\begin{array}{l}179,75 \mathrm{Ab} \\
144,00 \mathrm{Aa}\end{array}$ & $0,1-0,2 \mathrm{~m}$ & $\begin{array}{l}311,25 \mathrm{Aa} \\
150,00 \mathrm{Ba}\end{array}$ & 15,84 \\
\hline $\begin{array}{l}\text { Escarificado } \\
\text { Não - escarificado }\end{array}$ & $\begin{array}{r}120,25 \mathrm{Aa} \\
87,25 \mathrm{Aa}\end{array}$ & $0,2-0,3 \mathrm{~m}$ & $\begin{array}{r}132,50 \mathrm{Aa} \\
95,25 \mathrm{Aa}\end{array}$ & 18,97 \\
\hline $\begin{array}{l}\text { Escarificado } \\
\text { Não - escarificado }\end{array}$ & $\begin{array}{l}72,75 \mathrm{Aa} \\
49,75 \mathrm{Aa}\end{array}$ & $0,3-0,4 \mathrm{~m}$ & $\begin{array}{r}100,75 \mathrm{Aa} \\
67,00 \mathrm{Aa}\end{array}$ & 23,04 \\
\hline $\begin{array}{l}\text { Escarificado } \\
\text { Não - escarificado }\end{array}$ & $\begin{array}{l}57,50 \mathrm{Aa} \\
41,00 \mathrm{Aa}\end{array}$ & $0,4-0,5 \mathrm{~m}$ & $\begin{array}{l}70,50 \mathrm{Aa} \\
41,75 \mathrm{Aa}\end{array}$ & 19,13 \\
\hline $\begin{array}{l}\text { Escarificado } \\
\text { Não - escarificado }\end{array}$ & $\begin{array}{l}40,75 \mathrm{Aa} \\
24,50 \mathrm{Aa}\end{array}$ & $0,5^{-} 0,6 \mathrm{~m}$ & $\begin{array}{l}46,50 \mathrm{Aa} \\
25,00 \mathrm{Aa}\end{array}$ & 26,99 \\
\hline $\begin{array}{l}\text { Escarificado } \\
\text { Não - escarificado }\end{array}$ & $\begin{array}{l}794,00 \mathrm{Ab} \\
526,50 \mathrm{Ba}\end{array}$ & raízes até 0 & $\begin{array}{r}1130,00 \mathrm{Aa} \\
631,25 \mathrm{Ba}\end{array}$ & 10,79 \\
\hline $\begin{array}{l}\text { Escarificado } \\
\text { Não - escarificado }\end{array}$ & $\begin{array}{l}0,27 \mathrm{Aa} \\
0,31 \mathrm{Aa}\end{array}$ & lidade efetiva & $\begin{array}{l}0,26 \mathrm{Aa} \\
0,31 \mathrm{Aa}\end{array}$ & 7,12 \\
\hline
\end{tabular}

${ }^{(1)}$ Médias seguidas da mesma letra, maiúscula na coluna e minúscula na linha, não diferem entre si pelo teste de Tukey a $5 \%$. 
quantidade de raízes entre plantas de cobertura no tratamento não-escarificado revela que cada planta tem sua habilidade de crescer em condições adversas. Segundo Whiteley \& Dexter (1982), raízes de maior diâmetro (pivotantes) apresentam maior resistência ao encurvamento quando penetram em solo compactado, o que é importante em solos deficientes em macroporos, em que as raízes necessitam deformar mais o solo do que explorar fissuras. Para Shierlaw \& Alston (1984), as raízes finas (fasciculadas) teriam maior facilidade de penetrar nos solos compactados, por terem tamanho semelhante ao dos poros.

A profundidade efetiva, até onde se concentra $80 \%$ do sistema radicular (Klar, 1991), situou-se entre 0,26 e $0,31 \mathrm{~m}$ sem diferença entre os tratamentos (Quadro 3), o que demonstra que essas plantas teriam a mesma dificuldade para absorver água e nutrientes caso fossem expostas à deficiência hídrica.

Com relação ao crescimento das plantas cítricas, não foram observadas diferenças para perímetro do tronco, altura, diâmetro e volume da copa (Quadro 4). Esses valores estiveram abaixo do esperado para a região. Stenzel at al. (2005), ao avaliarem o desenvolvimento vegetativo e produtividade da laranjeira 'Folha Murcha' sobre seis porta-enxertos, com oito anos, em Londrina, no norte do Paraná, encontraram média de 3,58 m de altura, diâmetro da copa de 3,55 m e 23,73 $\mathrm{m}^{3}$ de volume da copa, ao passo que no presente trabalho esses valores médios foram de 3,11 $\mathrm{m}$ de altura, 3,00 $\mathrm{m}$ de diâmetro da copa e $17,52 \mathrm{~m}^{3}$ de volume da copa.

Para as variáveis referentes à produção, também não foram encontradas diferenças para número, massa dos frutos e produção por planta (Quadro 4). Levando-se em conta que a avaliação foi feita no primeiro ano após a implantação do experimento, podese considerar que os efeitos benéficos proporcionados pela escarificação ao solo foram neutralizados pelo corte das radicelas das plantas cítricas, que ocorre pela ação da escarificação. Ragozo et al. (2006) também não encontraram diferenças para o peso dos frutos e peso de frutos por planta ao avaliarem a produtividade da laranjeira 'Pêra' enxertada em limão ‘Cravo' cultivada por dois anos com feijão-de-porco (Canavalia ensiformis DC), lablabe (Dolichus lablab L.), guandu-anão (Cajanus cajan L. Millsp) e braquiária brizanta (Brachiaria brizantha Hochst ex A. Rich. Stafp). Esses autores atribuíram a falta de respostas ao período curto de tempo para realização da pesquisa.

Em trabalho realizado com a associação de feijãode-porco (Canavalia ensiformis L.) com escarificação nas entrelinhas do pomar de laranja 'Pêra' sobre limão 'Cravo', durante cinco anos, em duas localidades no Estado da Bahia, em comparação ao sistema

\section{Quadro 4. Crescimento e produção de plantas cítricas em pomar submetido à escarificação e plantas de} cobertura do solo

\begin{tabular}{|c|c|c|c|c|}
\hline \multirow[b]{2}{*}{ Manejo } & \multicolumn{3}{|c|}{ Coberturas do solo } & \multirow{2}{*}{ CV } \\
\hline & Vegetação espontânea & Guandu & Milheto & \\
\hline & \multicolumn{3}{|c|}{ Perímetro do tronco $(\mathrm{cm})$} & $\%$ \\
\hline Escarificado & $37,83 \mathrm{Aa}^{(1)}$ & $38,16 \mathrm{Aa}$ & $31,00 \mathrm{Aa}$ & \multirow{2}{*}{44,00} \\
\hline Não - escarificado & $36,66 \mathrm{Aa}$ & $34,00 \mathrm{Aa}$ & $36,83 \mathrm{Aa}$ & \\
\hline $\begin{array}{l}\text { Escarificado } \\
\text { Não - escarificado }\end{array}$ & $\begin{array}{l}3,15 \mathrm{Aa} \\
3,29 \mathrm{Aa}\end{array}$ & $\begin{array}{r}(\mathrm{m}) \\
3,29 \mathrm{Aa} \\
3,07 \mathrm{Aa}\end{array}$ & $\begin{array}{l}2,83 \mathrm{Aa} \\
3,01 \mathrm{Aa}\end{array}$ & 15,53 \\
\hline $\begin{array}{l}\text { Escarificado } \\
\text { Não - escarificado }\end{array}$ & $\begin{array}{l}3,33 \mathrm{Aa} \\
3,17 \mathrm{Aa}\end{array}$ & $\begin{array}{r}\text { a copa }(\mathrm{m}) \\
3,33 \mathrm{Aa} \\
3,00 \mathrm{Aa}\end{array}$ & $\begin{array}{l}2,00 \mathrm{Aa} \\
3,17 \mathrm{Aa}\end{array}$ & 20,25 \\
\hline $\begin{array}{l}\text { Escarificado } \\
\text { Não - escarificado }\end{array}$ & $\begin{array}{l}21,00 \mathrm{Aa} \\
17,83 \mathrm{Aa}\end{array}$ & $\begin{array}{c}\text { copa }\left(\mathrm{m}^{3}\right) \\
21,33 \mathrm{Aa} \\
15,66 \mathrm{Aa}\end{array}$ & $\begin{array}{l}12,66 \mathrm{Aa} \\
16,66 \mathrm{Aa}\end{array}$ & 21,37 \\
\hline $\begin{array}{l}\text { Escarificado } \\
\text { Não - escarificado }\end{array}$ & $\begin{array}{r}83,16 \mathrm{Aa} \\
125,83 \mathrm{Aa}\end{array}$ & $\begin{array}{l}\text { os por plant } \\
137,33 \mathrm{Aa} \\
151,83 \mathrm{Aa}\end{array}$ & $\begin{array}{r}84,16 \mathrm{Aa} \\
125,16 \mathrm{Aa}\end{array}$ & 33,93 \\
\hline $\begin{array}{l}\text { Escarificado } \\
\text { Não - escarificado }\end{array}$ & $\begin{array}{l}167,17 \mathrm{Aa} \\
171,67 \mathrm{Aa}\end{array}$ & $\begin{array}{l}\text { fruto }(\mathrm{g}) \\
172,16 \mathrm{Aa} \\
189,33 \mathrm{Aa}\end{array}$ & $\begin{array}{l}173,50 \mathrm{Aa} \\
179,46 \mathrm{Aa}\end{array}$ & 17,31 \\
\hline $\begin{array}{l}\text { Escarificado } \\
\text { Não - escarificado }\end{array}$ & $\begin{array}{l}13,48 \mathrm{Aa} \\
21,16 \mathrm{Aa}\end{array}$ & $\begin{array}{c}\text { planta }(\mathrm{kg}) \\
23,15 \mathrm{Aa} \\
24,76 \mathrm{Aa}\end{array}$ & $\begin{array}{l}14,08 \mathrm{Aa} \\
20,53 \mathrm{Aa}\end{array}$ & 58,33 \\
\hline
\end{tabular}

\footnotetext{
${ }^{(1)}$ Médias seguidas da mesma letra, maiúscula na coluna e minúscula na linha, não diferem entre si pelo teste de Tukey a 5 \%.
} 
tradicional com três capinas manuais nas linhas de plantio e três gradagens nas entrelinhas, foi constatado aumento do peso e número de frutos (Carvalho et al., 2002). Fidalski \& Stenzel (2006), após cinco anos de manejo, constataram redução na produção de frutos da laranjeira 'Folha Murcha' enxertada sobre limão 'Cravo', com as entrelinhas cultivadas com amendoim forrageiro (Arachis pintoi), em relação à grama-matogrosso (Paspalum notatum).

As médias das propriedades físicas do solo foram apresentadas considerando-se os tratamentos principais (escarificado e não-escarificado) em cada local de coleta, pela ausência de interação no fator cobertura do solo. Resultados semelhantes, indicando ausência de resposta das propriedades físicas do solo à utilização de plantas de cobertura, também foram obtidos por outros autores (Genro Junior et al., 2004; Nascimento et al., 2005).

Para a macroporosidade do solo no local do rodado, o tratamento escarificado teve maiores valores do que o não-escarificado nas profundidades de $0-0,1,0,1-$ 0,2 e 0,2-0,3 m, mas não houve diferença na profundidade de 0,3-0,4 m (Figura 1b), o que já era esperado, em razão da profundidade da escarificação. $\mathrm{Na}$ entrelinha do tratamento escarificado a macroporosidade foi superior à do não-escarificado, nas profundidades de $0-0,1$ e $0,1-0,2 \mathrm{~m}$, não se diferenciando nas profundidades de 0,2-0,3 e 0,30,4 m (Figura 1c). Resultados semelhantes foram encontrados por Secco et al. (2005) ao avaliarem diferentes empregos da escarificação no manejo do solo semestralmente, durante três anos. Em contrapartida, Minatel et al. (2006) não constataram aumento da macroporosidade do solo um ano após a escarificação num pomar cítrico.

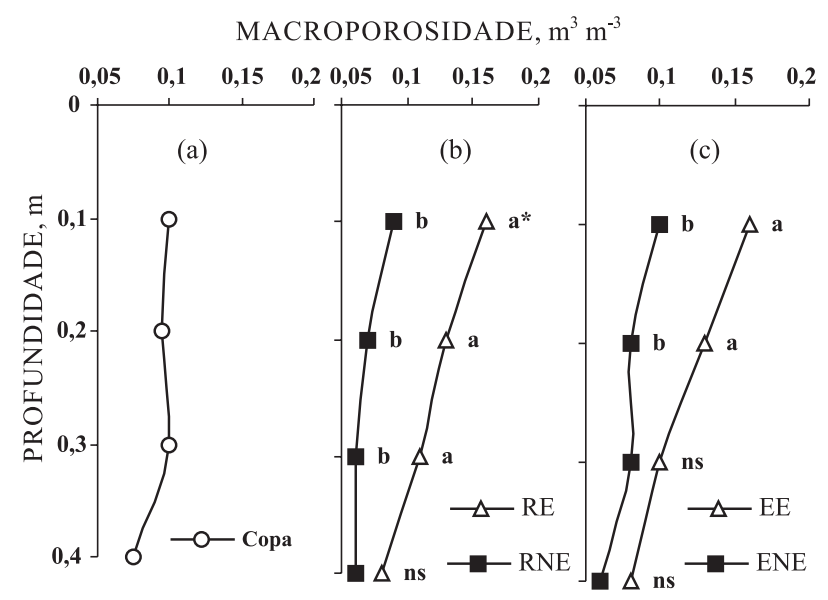

Figura 1. Macroporosidade do solo de pomar cítrico sob copa (a); no rodado escarificado (RE) e rodado não-escarificado ( $\mathrm{RNE})(\mathrm{b})$; e na entrelinha escarificada (EE) e entrelinha nãoescarificada (ENE) (c). ns: não-significativo. Médias seguidas por letras diferentes, a cada profundidade, diferem entre si pelo teste de Tukey a $5 \%$.
Constatou-se que nos locais onde não houve a escarificação, inclusive sob a copa, o valor de macroporosidade foi inferior a $0,10 \mathrm{~m}^{3} \mathrm{~m}^{-3}$ (Figura 1a, b,c), considerado restritivo ao crescimento e desenvolvimento radicular (Baver et al., 1972).

Para a densidade do solo no local do rodado, o tratamento escarificado foi inferior ao não-escarificado nas profundidades de 0-0,1 e 0,1-02 m e igual nas profundidades de 0,2-0,3 e 0,3-0,4 m (Figura 2b), enquanto na entrelinha o tratamento escarificado foi inferior ao não-escarificado em todas as profundidades avaliadas (Figura 2c). A redução da densidade do solo após a escarificação, assim como observado para o aumento da macroporosidade, corresponde aos resultados encontrados por Secco et al. (2005) e contraria os obtidos por Minatel et al. (2006).

Nos locais onde não houve a escarificação, inclusive a copa, os valores de densidade do solo oscilaram entre 1,3 e 1,4 $\mathrm{Mg} \mathrm{m}^{-3}$ (Figura 3a,b,c), considerados restritivos ao crescimento radicular em Latossolo de textura argilosa (Torres \& Saraiva, 1999). Esse impedimento mecânico reduz a taxa de elongação radicular devido à diminuição da divisão celular meristemática, o que resulta no engrossamento e achatamento das raízes em decorrência de danos causados no córtex (Torres \& Saraiva, 1999), explicando assim o já relatado fraco desempenho das plantas cítricas.

Ao observar os valores de macroporosidade e densidade do solo nos diferentes locais de coleta, podese constatar que sob a copa eles estão muito próximos dos valores do rodado e da entrelinha não-escarificados (Figuras 1a,b,c, 2a,b,c), confirmando a hipótese de que a compactação já estava presente quando da implantação do pomar, pois seria esperado que a densidade sob a copa fosse menor pela ausência de tráfego de máquinas e implementos, como verificado por Minatel et al. (2005).

Em se tratando da resistência do solo à penetração nos solos do rodado e da entrelinha, o tratamento escarificado teve menores valores do que o nãoescarificado nas três primeiras profundidades $(0-0,1$, 0,1-0,2 e 0,2-0,3 m); nas demais profundidades $(0,3-0,4,0,4-0,5$ e $0,5-0,6$ m) não foram constatadas diferenças (Figura 3b,c), o que evidencia o efeito da escarificação até a profundidade de trabalho do implemento.

Esses benefícios na diminuição da resistência do solo à penetração também foram encontrados por Secco et al. (2004) com escarificação (a 0,20 m de profundidade) em solo argiloso. Por sua vez, Minatel et al. (2006) constataram que a subsolagem (a 0,40 m de profundidade) em pomar cítrico num Latossolo Vermelho distroférrico não alterou a resistência do solo à penetração, fato que pode ser atribuído ao tempo de um ano transcorrido entre a subsolagem e a avaliação por aqueles autores. De acordo com Tormena et al. (2002), nesse tipo de manejo do solo são necessárias avaliações de médio-longo prazo, em face das mudanças dinâmicas na qualidade física do solo. 
DENSIDADE DO SOLO, $\mathrm{Mg} \mathrm{m}^{-3}$

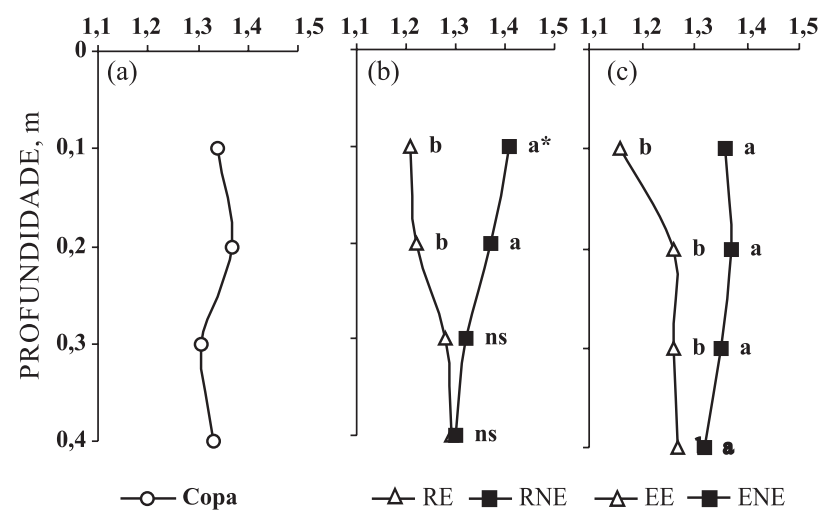

Figura 2. Densidade do solo de pomar cítrico sob a copa (a); no rodado escarificado (RE) e rodado não-escarificado (RNE); (b); e na entrelinha escarificada (EE) e entrelinha não-escarificada (ENE) (c). ns: não-significativo. Médias seguidas por letras diferentes, a cada profundidade, diferem entre si pelo teste de Tukey a $5 \%$.
Nas profundidades abaixo de $0,3 \mathrm{~m}$, nos três locais avaliados, os valores da resistência do solo à penetração ficaram entre 3 e $4 \mathrm{MPa}$ (Figura 3a,b,c), considerados restritivos ou mesmo impeditivos ao crescimento radicular (Beutler \& Centurion, 2003), sobretudo quando se considera que a resistência foi avaliada quando o solo estava com umidade entre 0,23 e $0,27 \mathrm{~kg} \mathrm{~kg}^{-1}$, independentemente do local e da profundidade de coleta (Figura 3d). Segundo Genro Junior et al. (2004), para o tipo de solo deste trabalho, esses valores de umidades estão numa faixa intermediária entre o ponto de murcha permanente e a capacidade de campo - faixa em que não se espera tão elevada resistência do solo a penetração.

A compactação do solo encontrada no trabalho, por ocorrer também sob a copa das plantas, onde as passagens de implementos aconteceram somente no momento da instalação do pomar, pode ser atribuída ao efeito do cultivo da cana-de-açúcar anterior ao plantio dos citros, que demanda tráfico intenso de máquinas, podendo ocasionar altos valores de

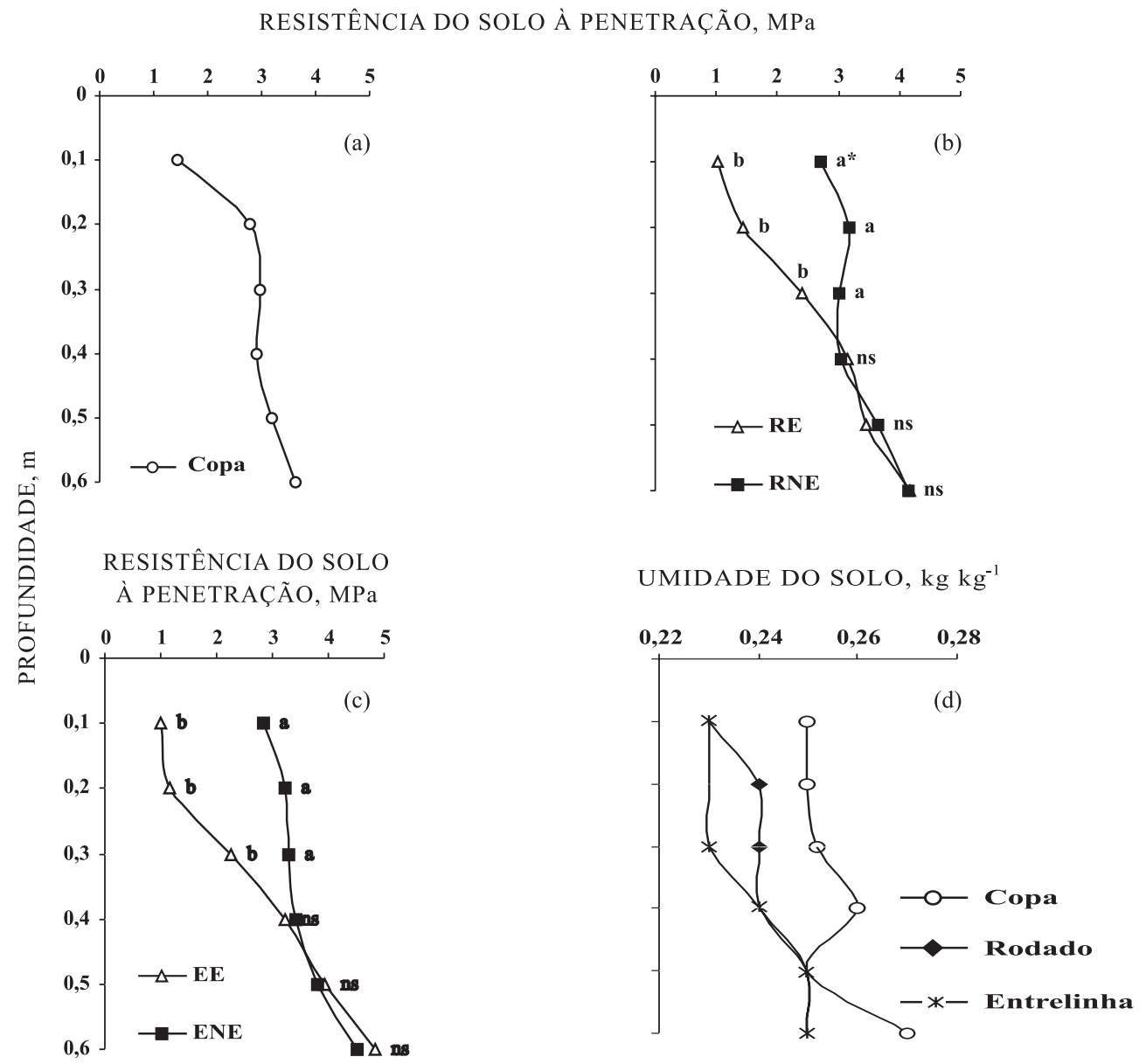

Figura 3. Resistência do solo à penetração em pomar cítrico sob a copa (a); no rodado escarificado (RE) e rodado não-escarificado (RNE) (b); na entrelinha escarificada (EE) e entrelinha não-escarificada (ENE) (c); e umidade do solo (d). ns: não-significativo. Médias seguidas por letras diferentes, a cada profundidade, diferem entre si pelo teste de Tukey a $5 \%$. 
resistência à penetração do solo em profundidades maiores (Iaia et al., 2006).

\section{CONCLUSÕES}

1. O crescimento (massa) da parte aérea do guandu e a do milheto aumentaram com a escarificação do solo.

2. O crescimento do sistema radicular do milheto foi maior que o do guandu no solo escarificado, porém no manejo não-escarificado o número de raízes não foi diferente entre as duas espécies.

3. O crescimento e a produção das plantas cítricas não foram influenciados pela escarificação e pelas plantas de cobertura do solo.

4. Houve aumento da macroporosidade e redução da densidade e da resistência do solo à penetração com a escarificação.

\section{AGRADECIMENTOS}

Os autores agradecem à sra. Jennifer Kaphan, pelas condições proporcionadas para a realização do trabalho, e ao CNPq, pelo suporte financeiro.

\section{LITERATURA CITADA}

ALVARENGA, R.C.; LARA CABEZAS, W.A.; CRUZ, J.C. \& SANTANA, D.P. Plantas de cobertura de solo para sistema plantio direto. Inf. Agropec., 22:25-36, 2001.

ALVARENGA, R.C.; COSTA, L.M.; MOURA FILHO, W. \& REGAZI, A.J. Características de alguns adubos verdes de interesse para a conservação e recuperação de solos. Pesq. Agropec. Bras., 30:175-185, 1995.

ANDRETTA, G.M.A.C. Valor bruto da produção agropecuária paranaense de 2005. Curitiba, SEAB/DERAL/DEB, 2007. $84 \mathrm{p}$.

BAVER, L.D.; GARDNER, W.H. \& GARDNER, W.R. Soil physics. 4.ed. New York, John Wiley \& Sons, 1972. 529p.

BEUTLER, A.N. \& CENTURION, J.F. Efeito do conteúdo de água e da compactação do solo na produção de soja. Pesq. Agropec. Bras., 38:849-856, 2003.

BÖHM, W. Methods of studying root systems. Berlin, Springer Verlag, 1979. 188p.

CARVALHO, J.E.B.S.; LUCIANO, S.; CALDAS, R.; ANTAS, P.E.U.T.; ARAÚJO, A.M.A.L; LOPES L. C.; SANTOS, R.C.; LOPES, N.C.M. \& SOUZA, A.L.V. Leguminosa no controle integrado de plantas daninhas para aumentar a produtividade da laranja-'Pêra'. R. Bras. Frutic., 24:8285, 2002.
EMPRESA BRASILEIRA DE PESQUISA AGROPECUÁRIA EMBRAPA. Manual de métodos de análise de solos. Rio de Janeiro, 1997. 212p.

EMPRESA BRASILEIRA DE PESQUISA AGROPECUÁRIA EMBRAPA. Sistema brasileiro de classificação de solos. Rio de Janeiro, 1999. 412p.

FEICHTENBERGER, E.; BERETTA, M.J.G. \& HARAKAWA, R. Manejo integrado das principais doenças fúngicas e bacterianas dos citros. In: SEMINÁRIO INTERNACIONAL DE CITROS-MIP, 3., Bebedouro, 1994. Anais. Campinas, Fundação Cargill, 1994. p.291310.

FIDALSKI, J. \& STENZEL, N.M.C. Nutrição e produção da laranjeira "Folha Murcha" em porta-enxertos e plantas de cobertura permanente na entrelinha. Ci. Rural, 36:807$813,2006$.

GENRO JUNIOR, S.A.; REINERT, D.J. \& REICHERT, J.M. Variabilidade temporal da resistência à penetração de um Latossolo argiloso sob semeadura direta com rotação de culturas. R. Bras. Ci. Solo, 28:477-484, 2004.

GONÇALVES, W.G.; JIMENEZ, R.L.; ARAÚJO FILHO, J.V.; ASSIS, R.L.; SILVA, G.P. \& PIRES, F.R. Sistema radicular de plantas de cobertura sob compactação do solo. Eng. Agríc., 26:67-75, 2006.

IAIA, A.M.; MAIA, J.C.S. \& KIM, M.E. Uso do penetrômetro eletrônico na avaliação da resistência do solo cultivado com cana-de-açúcar. R. Bras. Eng. Agríc. Amb., 10:523530,2006

INSTITUTO AGRONÔMICO DO PARANÁ - IAPAR. Manual de análise química do solo e controle de qualidade. Londrina, 1992. 40p. (Circular Técnico, 76)

KLAR, A.E. Irrigação; freqüência e quantidade de aplicação. São Paulo, Nobel, 1991. 156p.

MENDEL, K. Rootstock-scion relationships in Shamouti trees on light soil. Ktavim, 6:35-60, 1956.

MINATEL, A.L.G.; ANDRIOLI, I.; CENTURION, J.F. \& NATALE, W. Efeitos da subsolagem e da adubação verde nas propriedades físicas do solo em pomar de citros. Eng. Agríc., 26:86-95, 2006.

NASCIMENTO, J.T.; SILVA, I.F.; SANTIAGO, R.D. \& SILVA NETO, L.F. Efeito de leguminosas nos atributos físicos e carbono orgânico de um Luvissolo. R. Bras. Ci. Solo, $29: 825-831,2005$.

RAGOZO, C.R.A.; LEONEL, S. \& CROCCI, A.J. Adubação verde em pomar cítrico. R. Bras. Frutic., 28:69-72, 2006.

REZENDE, J.O.; MAGALHÃES, A.F.J.; SHIBATA, R.J.C.; BRANDÃO, F.J.C. \& REZENDE, V.J.R.P. Citricultura nos solos dos tabuleiros costeiros: Análise e sugestões. Salvador, SEAGRI/SPA, 2002. 97p.

SECCO, D.; DA ROS, C.O.; SECCO, K. \& FIORIN, E.J. Atributos físicos e produtividade de culturas em um Latossolo Vermelho argiloso sob diferentes sistemas de manejo. R. Bras. Ci. Solo, 29:407-414, 2005.

SECCO, D.; REINERT, D.J.; REICHERT, J.M. \& DA ROS, C.O. Produtividade de soja e propriedades físicas de um Latossolo submetido a sistemas de manejo e compactação. R. Bras. Ci. Solo, 28:797-804, 2004. 
SHIERLAW, J. \& ALSTON, A.M. Effects of soil compaction on root growth and uptake of phosphorus. Plant Soil, 77:1528, 1984.

SILVA, R.H. \& ROSOLEM, C.A. Crescimento radicular de soja em razão da sucessão de cultivos e da compactação do solo. Pesq. Agropec. Bras., 37:855-860, 2002.

SILVEIRA, G.M. O preparo do solo; implementos corretos. Rio de Janeiro, Globo, 1988. 243p.

STENZEL, N.M.C.; NEVES, C.S.V.J.; GONZALEZ, M.G.N.; SCHOLZ, M.B.S. \& GOMES, J.C. Desenvolvimento vegetativo, produção e qualidade dos frutos da laranjeira 'Folha Murcha' sobre seis porta-enxertos no norte do Paraná. Ci. Rural, 35:1281-1286, 2005.

STOLF, R.; FERNANDES, J. \& FURLANI NETO, V.L. Recomendação para uso do penetrômetro de impacto modelo IAA/PLANALSUCAR-STOLF STAB. Açúc. Álcool Subprod., 3:18-23, 1983.
SUZUKI, L.E.A.S. \& ALVES, M.C. Fitomassa de plantas de cobertura em diferentes sucessões de culturas e sistemas de cultivo. Bragantia, 65:121-127, 2006.

TERSI, F.E.A. \& ROSA, S.M. A subsolagem no manejo de solo para os pomares de citros. Laranja, 16:289-298, 1995.

TORMENA, C.A.; BARBOSA, M.C.; COSTA, A.C.S. \& GONÇALVES, A.C.A. Soil bulk density, porosity and resistance to root penetration in an Oxisol managed by different soil tillage systems. Sci. Agric., 59:795$801,2002$.

TORRES, E. \& SARAIVA, O.F. Camadas de impedimento mecânico do solo em sistemas agrícolas com soja. Londrina, Embrapa-CNPSo, 1999. 58p. (Circular Técnica, 23)

WHITELEY, G.M. \& DEXTER, A.R. Root development and growth of oilseed, wheat and pea crops on tilled and nontilled soil. Soil Till. Res., 2:379-393, 1982. 